\title{
SWOT Analysis on Medical Informatics and Development Strategies
}

\author{
Xiaoyan $\mathrm{Ma}^{1}$, Zhongdong $\operatorname{Han}^{1} \&$ Hua $\mathrm{Ma}^{1}$ \\ ${ }^{1}$ School of Information and Engineering, Taishan Medical University, Taian, Shandong, China \\ Correspondence: Xiaoyan Ma, School of Information and Engineering, Taishan Medical University, Taian, \\ Shandong, China. E-mail: maxiaoyan81@126.com
}

Received: December 1, 2014

Accepted: March 23, $2015 \quad$ Online Published: March 23, 2015

doi:10.5539/hes.v5n2p21

URL: http://dx.doi.org/10.5539/hes.v5n2p21

\begin{abstract}
This article aims at clarifying the strategic significance of developing medical informatics, conducting SWOT analysis on this discipline and hence establishing the strategic objectives and focal points for its development.
\end{abstract}

Keywords: medical informatics, strategy, SWOT

\section{Introduction}

With the increasingly significant role of disciplines in the competition among universities, the recent years has witnessed widespread attention to the importance of disciplinary construction. Meanwhile, with the popularity of the computer and Internet, medical science has got more collision, intersection and even fusion with informatics. It is the shared theoretical basis and methodology that have combined them into medical informatics which serves as a scientific basis for the theory, method and application of informatics in the medical field, involves new methods and theories related to effective establishment, acquisition, integration, management and optimization of data and knowledge in medical science and deals with the application of them into medical informatics theories. This new discipline, medical informatics (Wang, 2009), which falls into the category of medical science, is by nature an interdisciplinary field covering both informatics and medical science. Previously it was called medical computer science, medical information science and the application of the computer to medical science.

\subsection{The Significance of a Research on the Development Strategies of Medical Informatics}

Currently, disciplinary development has displayed a trend with overlapping and fusion to a large extent (Zhang, 2003), which requires adaptations in development strategies to their reality and external environment. After 40 years' development, researches on the theory, application and technology of medical informatics have got some achievements, most of which is focused on the application level, hence leading to laggard development in talents. Therefore, theoretical researches on definition, research subject and content seem obviously insufficient together with unclear positioning of medical informatics and incomplete understanding of the significance of this discipline. Such a research on development strategies, of great importance for the development of medical informatics, is bound to propel medical research and provide reference for the strategic decisions on medical care.

\subsection{Content and Methods of Strategic Research on Medical Informatics}

Literature research, literature metrology, SWOT analysis and interviews with experts are utilized in this research to clarify the thought, objectives, future focal fields and tasks for medical informatics.

\subsection{Environmental Analysis on Medical Informatics}

Medical informatics (Liu, 2003) is intended to realize effective management over medical information to fully use and share it, to accelerate the transformation from medical information to knowledge or from knowledge to intelligence, to propel the overall development of medical science. The environment for medical informatics is composed of external environment, which, the macro-environment, includes legitimate, economic, social, technological factors and exerts indirect influences on disciplinary development, and internal one, which, composed of current disciplinary system, is a comprehensive whole of all factors controlled by disciplinary development and mainly includes resources and capacities. At present, the general system covers researches on theories, framework, construction of echelon, training of talents, construction of directions, construction of 
scientific researches and bases, relevant magazines, the relations among bioinformatics, medical informatics and information science.

\section{SWOT Analysis on Medical Informatics}

\subsection{Opportunities}

The development of a discipline is determined by social demands for it. Likewise, to what extent the theoretical system of a discipline is perfect is determined by how well it satisfies social demands. The recent six and seven decades has witnessed prosperous development of medical science around the world and a boom of medical research in developed countries. Informatization and sharing of scientific data are of great significance for the advance of medical science and the security of human health. With greater attention to medical science, there is increasing demands for medical science data by the world or nations.

With informatization being a major trend for current global development, the government is enhancing the informatization process, establishing practical and shared system of medical care information and greatly promoting medical care information construction.

\subsection{Challenges}

\subsubsection{Poor Foundation for Medical Informatics}

Compared with foreign countries, China's medical informatics has undergone different processes of development. Originating from medical library and information science, China's medical informatics, compared with the foreign one based on hospital information system, has poor foundation at the very beginning. This discipline aims at making use of the knowledge from medical research to develop and assess a variety of methods and systems to obtain, process and explain patients' data with the computer. Medical library and information science, emphasizing the processing medical literature, fails to develop students' strong capacity in computer technology and to meet the actual demands of applying computer technology to the management of medical data and information. Up to now, however, there is no profound and clear knowledge of the concept and nature of medical information science in China, where many still put equal importance to medical information science and medical library and information science or even some may regard the teaching process of medical information science as teaching how to retrieve medical information. Such a narrow-minded knowledge is disadvantageous for the development of China's medical information science.

\subsubsection{Unreasonable Teaching System of Medical Information Science}

In 2003, the National Educational Ministry officially listed medical information science a major outside higher education directory, which is not an official major in medical colleges. In more than 30 medical universities and colleges in China which have established the information management and information system major, its teaching cannot satisfy the demands for the development of medical information. Due to the lack of curriculum system and teaching materials fit for these universities and colleges, their teaching content tends to be diverse. Some universities merely mingle the teaching of medical courses with that of computer ones, hence lacking in organic correlation, failing to cover how to manage medical information, being unable to reflect interdisciplinarity as well as the specialty and complexity of medical information. Some universities have even transferred this major into the second computer science major whose students are cultivated for public information management for their future career, hence failing to meet the needs for information management in hospital.

\subsubsection{Restriction from Traditional Management Theories}

In the current era emphasizing knowledge economy, due to its fundamental defects, traditional information management theories have plunged hospital information management into embarrassment and informatization construction into a dilemma and even caused many people's doubt about the value to invest in medical information.

\subsection{Disciplinary Advantages}

With the application of information technology and computer technology to medical research, digitalization and networking of medical information are given technical support and therefore dramatic changes have taken place in medical information.

\subsection{Disciplinary Disadvantages}

Disadvantages include no common knowledge about disciplinary framework, imbalanced development in medical information research fields, a lack of talent cultivation institution, no professional team for medical 
information, no platform for exchange on medical information, no disciplinary culture of medical information.

\section{Development Strategies of Medical Information}

\subsection{Defining the Function of Discipline}

Seen from the function and role of a discipline, the function of medical information is manifested in the following aspects:

First is scientific research. Relevant theoretical and applied researches can help to perfect the disciplinary system of medical informatics and promote the development of medical informatics and disciplinary innovation.

Second comes the cultivation of talents. Talents of all sorts and all levels should be cultivated to form the core strength for the constant development of medical information cause.

Third is social service. Outcomes from the application and development of medial informatics should be applied to information service and social development.

\subsection{Perfecting Disciplinary Construction and Management System and Confirming the Position of Medical Informatics in the Disciplinary System}

Up to now, interdisciplinary courses or interdisciplinary science is merely a general concept for some interwoven disciplines in many people's minds with no awareness of their distinctive role in the development process of science. As a result, corresponding disciplinary construction and adjustment in management institution fail to keep up with the trend.

In order to turn the odds, relevant researchers are expected to persist in calling for more distant trans-disciplinary researches and interdisciplinary science, publicizing their feature, position and role whatever opportunities, occasions and channels can be utilized. In this way, great importance will be attached to this issue, which may lead to new institutional arrangement to put distant trans-disciplinary researches and interdisciplinary science into the management process. Before that, a green channel should be opened up for the application and accreditation of the projects or research achievements on distant trans-disciplinary researches and interdisciplinary science to serve as an actual encouragement and support for them.

\subsection{Emphasizing Curriculum Construction}

Medical informatics, a newly-born discipline, has no strict and definite curricular setting and teaching content. A majority of medical colleges accept medical informatics as a subject in which medical students are given knowledge on the latest application of information technology, they can learn more about the potential and shortage of the application of the computer in medical science and therefore complex talents informed of both medical science and information science can be cultivated. By contrast, in US, medical informatics is further divided into 5 parts including computer science, biological medical science, decisive science, social science and public policies. Computer technology and medical knowledge are the two cores for medical informatics. During the learning process of medical informatics, students have access to biological information, graphical information and clinical knowledge and attach emphasis on decision making and quantitative computation. In terms of content, the following aspects can be included:

(1) An Introduction to Medical Informatics

Students can be given a general knowledge on medical informatics, including the concept, background and significance of medical informatics, the relations between it and other relevant disciplines and its development prospect.

(2) The Application of the Computer to Medical Informatics

The principle in which the computer assists human reasoning in the diagnosis-treatment cycle is introduced with the critical point attached to the different levels on which computer technology can be applied to endow students with the correct idea on the application of the computer in medical science including in what fields the computer functions remarkably, in what aspects there are disadvantages, what missions are beyond its' capacity and so on.

\section{(3) Hospital Information System}

This covers the concept, development, composition, function, mode of construction of hospital information system as well as the current situation of Chinese hospitals' information system and illustrated functions.

(4) Medical Case Management 
This aspect includes the history, function, the characteristics and shortcomings of modern medical records, the concept and advantages of electronic medical records, the composition of electronic medical records, its development in different nations, illustrated functions and prospects of electronic medical records.

\section{(5) Support System for Medical Decisions}

In this aspect, the concept, function, characteristics of such a system, the basic methods for decision support, construction technology and implementation procedures of such a system and illustrated functions are mentioned.

\section{(6) Distant Medical Science}

Distant medical science is a rapidly developed area of medical informatics in recent years. In terms of this branch, its concept and relevant disciplines, the general introduction of its development in foreign countries, the current situation of China's distant medical science, its applications, its technology and allocation, illustrated function and prospects.

\section{Conclusion}

As a new interdisciplinary field, medical informatics is undergoing its rapid development. Some problems and tendencies are shown in a systematic analysis on medical informatics which is expected to propel more efficient development of China's medical informatics.

\section{Acknowledgements}

This project is funded by the Social Science Planned Project of Taian. (No. 13skx020)

\section{References}

Liu, Z. G., \& Lv, L. X. (2003). A Research on Medical Informatics and Teaching Content. Medical Information, $2,123-124$.

Wang, X. K. (2009). Distant Trans-disciplinary Research and Development of Interdisciplinary Science. Zhejiang Social Science, 1, 16-21.

Zhang, L. (2003). On Interdisciplinary Science Research and Medical Informatics. Medical Information, 9, 168-169.

\section{Copyrights}

Copyright for this article is retained by the author(s), with first publication rights granted to the journal.

This is an open-access article distributed under the terms and conditions of the Creative Commons Attribution license (http://creativecommons.org/licenses/by/3.0/). 